\title{
VIVENCIANDO INGLÊS COM KAHOOT
}

\author{
Experiencing English with Kahoot
}

\author{
Maria Aparecida GAZOTTI-VALLIM \\ Instituto Federal de São Paulo (IFSP), São Paulo, Brasil \\ Silvia Trentin GOMES \\ Pontifícia Universidade de São Paulo (PUCSP), São Paulo, Brasil \\ Cynthia Regina FISCHER \\ Instituto Federal de São Paulo (IFSP), São Paulo, Brasil
}

\begin{abstract}
Resumo: Este artigo visa a apresentar duas atividades elaboradas na plataforma digital Kahoot que fazem parte de uma unidade didática para o ensino de inglês como língua estrangeira e analisar seu potencial para o desenvolvimento de aprendizagem significativa, segundo Carl Rogers. Para o autor, esse tipo de aprendizagem parte das necessidades e interesses do aprendiz e deve fazer sentido em sua vida pessoal, mobilizando aspectos emocionais e cognitivos. O Kahoot foi utilizado com o intuito de inserir um recurso tecnológico interativo que se apropria de elementos dos jogos (gamificação) para engajar os usuários na aprendizagem de língua inglesa. Essas atividades foram aplicadas em três aulas de sessenta minutos para duas alunas de dez e quinze anos e objetivaram descrever caracteristicas fisicas e da personalidade de duas pessoas famosas indicadas pelos aprendizes. As atividades fazem parte da unidade didática cujo objetivo é ensinar como descrever pessoas famosas. Percebeu-se que o trabalho proposto foi adequado para o desenvolvimento da aprendizagem significativa.
\end{abstract}

PALAVRAS-CHAVE: Recurso educacional digital. Jogos. Aprendizagem significativa. Ensino-aprendizagem de inglês como língua estrangeira.

\footnotetext{
Abstract: This article aims to present two activities to teach English as a Foreign Language created on the Kahoot digital learning platform and to analyze their potential for developing significant learning, as defined by Carl Rogers. The author understands this type of learning as based on the learner's needs and interests and as part of his/her personal life, involving feeling and cognitive aspects. Kahoot was used with the intention of inserting an interactive technological resource to teach English and makes use of gamification to engage users in learning this language. The activities analyzed here compose a didactic unit to teach how to describe famous people. They were taught in three six-minute classes for two students aged 10 and 15 and focused on describing physical and personality traits of two famous people chosen by the students. It was noticed that the proposal was adequate for the development of significant learning.
} 
KEYWORDS: Digital Educational Resource. Games. Significant learning. Teaching/learning English as a Foreign Language.

\section{Introdução}

Nas últimas décadas a necessidade de incluir o uso de Tecnologias Digitais de Informação e Comunicação (TDIC) nas escolas vem sendo bastante discutida e várias tentativas de implementação de recursos tecnológicos em sala de aula têm sido realizadas não apenas no contexto de escolas particulares como também em escolas públicas. O Projeto Nacional de Informática na Educação (ProInfo) ${ }^{1}$ criado em 1997 (BRASIL, 1997) e os programas como Banda larga nas escolas (PBLE) (BRASIL, 2008) ${ }^{2}$ e Um computador por aluno (BRASIL, 2012) ${ }^{3}$, entre outros, corroboram essa tendência e, mais recentemente, pesquisas demonstram que a utilização de dispositivos móveis como recursos didáticos para o ensino-aprendizagem (mobile learning) podem contribuir para a melhoria de muitas práticas pedagógicas existentes (BOTTENTUIT JR., 2012). Nesse sentido, Wolynec (2010) salienta que a aprendizagem móvel é um padrão emergente que reúne três paradigmas extremamente requisitados pela atual geração de estudantes: modelo flexível de aprendizagem; padrão pedagógico apoiado em dispositivos tecnológicos sem fios e diretrizes voltadas essencialmente para a aprendizagem centrada no aluno. (WOLYNEC, 2010).

Com base nesse pressuposto e considerando a necessidade de fácil acesso ao equipamento, além do fato de $85 \%$ de jovens usuários da internet entre 15 e 19 anos utilizarem o celular como principal dispositivo para conexão ${ }^{4}$, procuramos ferramentas digitais disponíveis via celular para criar atividades para o ensino de inglês como língua estrangeira para adolescentes.

Dentre as possibilidades existentes para tanto, optamos pela utilização de uma plataforma para a elaboração de jogos educativos digitais pelo fato de o ato de jogar online ser bastante frequente na faixa infanto-juvenil, tendo sido apontado como a quarta atividade mais realizada pelo público infantil em uma pesquisa do Comitê Gestor da

${ }^{1} \mathrm{O}$ objetivo ProInfo visa à disseminação do "uso pedagógico das tecnologias de informática e telecomunicações nas escolas públicas de ensino fundamental e médio pertencentes às redes estadual e municipal.”(BRASIL, 1997/2012).

${ }^{2} \mathrm{O}$ objetivo deste programa é conectar as escolas públicas urbanas à internet por meio de "tecnologias que propiciem qualidade, velocidade e serviços para incrementar o ensino público no País." (BRASIL, 2008).

${ }^{3}$ Este projeto foi restabelecido pela Lei 12.715, que propõe o incentivo da compra de computadores para uso educacional (um computador por aluno) e da adesão ao Programa Nacional de Banda Larga.

${ }^{4}$ Dados relatados na pesquisa Juventude Conectada 2 (FUNDAÇÃO TELEFÓNICA VIVO, 2016). 
Internet no Brasil em $2012^{5}$. A plataforma usada para o desenvolvimento das atividades propostas neste artigo é o Kahoot, uma plataforma interativa que utiliza elementos dos jogos, uma das características presentes no processo de gamificação ${ }^{6}$, para estimular o desafio, a curiosidade e o envolvimento dos usuários em experiências que impactem positivamente sua performance.

Nessa plataforma foram criadas duas atividades com o objetivo de ensinar vocabulário específico para descrever pessoas fisicamente e caracterizar suas personalidades. Tais atividades fazem parte de uma unidade didática que visa a ensinar alunos iniciantes em língua inglesa a descrever pessoas famosas indicando suas profissões, informações pessoais, características físicas e de personalidade, principais trabalhos e rotina diária.

O intuito deste artigo é, portanto, apresentar tais atividades e discutir seu potencial como instrumento para proporcionar uma oportunidade de desenvolver a aprendizagem significativa por meio de uma plataforma que utiliza elementos que caracterizam os jogos.

\section{Fundamentação teórica}

Segundo Alves (2014), promover condições para que o processo de ensinoaprendizagem seja algo motivador e prazeroso para todos os envolvidos é um dos grandes desafios da educação. Nesse sentido, a autora defende que a inserção de jogos no contexto educacional e a utilização de seus elementos de mecânica, estética e pensamento (trabalhando juntos) pode propiciar a possibilidade de produzir experiências engajadoras.

Pensando em criar oportunidades para que os alunos se engajem no processo de ensino-aprendizagem, vemos o jogo como um recurso importante a ser inserido no contexto educacional. Mas afinal o que é jogo? no que se constitui? o que possui? e para quê?

De acordo com Petry (2010), existe uma grande diversidade de aplicações, ações, assim como definições do jogo, podendo acontecer que um mesmo conceito nem sempre "corresponda aos mesmos fenômenos" (PETRY, 2010, p.30). Entretanto, mesmo com diferentes definições, sentidos e linguagens, o que parece essencial para a caracterização de um jogo é que ele não apenas colabore, mas também constitua-se na construção do

\footnotetext{
5 A TIC Kids online Brasil entrevistou crianças e adolescentes entre 9 -16 anos (COMITÊ GESTOR DA INTERNET NO BRASIL, 2012).

${ }^{6}$ Blanco (2015) afirma que o termo gamificação (do inglês gamification) foi mencionado pela primeira vez por Nick Pelling e, no ano de 2010, com a designer de games norte americana Jane McGonigal, começou a ganhar popularidade a partir de uma apresentação sobre como os jogos podem fazer um mundo melhor por meio de um TED talk.

Technology, Entertainment, Design talks (TED talks) são vídeos de apresentações realizadas pela fundação americana Sapling, sem fins lucrativos que tem por objetivo disseminar ideias. (TED, 2017).
} 
conhecimento (PETRY, 2014). Huizinga (2012) afirma que o jogo se constitui como formador da cultura humana e Zimmeerman (2004) o define como "um sistema no qual jogadores se engajam em um conflito artificial, definido por regras, que resultam em um resultado quantificável” (ZIMMEERMAN 2004, p. 96). Já Heinch et al (2002, p. 10) definem o jogo como

uma atividade em que os participantes seguem regras prescritas que diferem das da vida real através do esforço para alcançar uma meta ambiciosa. (HEINCH et al, 2002, p. 10).

Costikyan (1994), por sua vez, descreve-o como "a forma de arte na qual os participantes, denominados jogadores, tomam decisões com a finalidade de gerenciar recursos utilizando fichas para atingir um objetivo." (COSTIKYAN, 1994, p. 16). Dessa forma, tanto um jogo analógico quanto um jogo digital pode ser considerado um poderoso elemento cultural construtor de conhecimento e capaz de engajar os jogadores em um conflito artificial definido por regras e visando a alcançar um objetivo.

Ainda segundo o autor, esse engajamento dos jogadores acontece a partir da mobilização dos elementos dos jogos capazes de envolvê-los e motivá-los de forma a produzir determinadas experiências de aprendizagem. Werbach (2012 apud ALVES, 2014) entende os elementos presentes em jogos como "padrões regulares que podem ser combinados de diferentes maneiras para que você construa um jogo" e que se encontram "dentro de uma mecânica, dinâmica e estética". (WERBACH apud ALVES, 2014, p. 41). A mecânica diz respeito a elementos ligados à ação, já a dinâmica engloba os elementos conceituais e os componentes dos jogos estão relacionados à sua estética. A mobilização de emoções; o contar com a sorte; a organização dos jogos por meio de narrativas, progressão e relacionamento, desafios, atividades de cooperação e competição; a existência de feedback rápido, recompensas, níveis, pontos, investigação ou exploração, placar, barra de progressão, recursos já coletados, gráfico social etc. são alguns dos elementos componentes dos jogos. Segundo Kapp (2012), todos esses elementos podem ser utilizados em sala de aula ou em qualquer outro contexto para inferir à situação elementos característicos de um jogo, sem que exista um jogo propriamente dito.

Deterding et al (2011) refere-se ao uso de elementos dos jogos fora de seu contexto com o objetivo de despertar o interesse e envolvimento das pessoas como gamificação. Além de ser inserida na educação, a gamificação é utilizada em diversos setores, especialmente no marketing, saúde, política, transportes e nos esportes por meio de aplicações gamificadas (KAPP, 2012).

Segundo Malone (1981), os elementos que constituem os jogos podem estimular a participação dos indivíduos por meio da motivação intrínseca, ou seja, o interesse em engajar-se na própria atividade sem ser por recompensa financeira ou status, simplesmente por ela despertar a curiosidade, a fantasia e o desafio. 
Jogos do cotidiano, jogos educativos bem como a gamificação podem ser utilizados em sala de aula. É importante ressaltar, no entanto, que os jogos educativos são produzidos como jogos, com elementos de jogos e usados como tal, porém possuem uma finalidade educativa e não apenas de simples diversão. Assim, é essencial lembrar que não apenas a motivação deve ser o foco de um jogo educativo, objetivos e princípios de aprendizagem precisam ser definidos com base na linguagem (verbal e não verbal) e na teoria de ensino-aprendizagem nas quais as atividades estão fundamentadas. Segundo Gee (2009), para que um jogo seja educativo, ele deverá ser jogado, dentro ou fora das escolas, com sentido reflexivo e estratégico. Portanto, é essencial que o professor analise detalhadamente um jogo, seja ele analógico ou digital, antes de personalizá-lo ou inserilo em seu contexto de ensino-aprendizagem.

A evolução tecnológica trouxe uma transformação cultural de forma rápida e os jogos digitais, também chamados de virtuais, eletrônicos, on-line ou games ${ }^{7}$, suas ferramentas e interfaces vem sendo cada vez mais utilizadas com o objetivo de potencializar a aprendizagem e interação dos seus usuários.

A utilização de jogos digitais para o ensino inglês vem aumentando na última década. Dentre alguns estudos com foco nessa área, podemos mencionar os estudos de: Barcelos (2010), que investigou a relação estabelecida pelos alunos de uma escola pública em Uberaba/MG entre o uso de jogos on-line e a aprendizagem de língua inglesa; Silveira (2012), com a pesquisa sobre a importância dos recursos tecnológicos na aprendizagem dessa língua em contextos formais e informais; Oliveira e Oliveira (2016), que elencaram e analisaram jogos digitais para computadores e dispositivos móveis que podem ser usados para a aprendizagem de inglês com vistas a informar a Secretaria de Educação Municipal de Patrocínio (MG) para subsidiar ações para a integração da tecnologia digital ao ensino de línguas e Araújo (2016), que apresentou uma análise de jogos digitais disponíveis on-line realizada por professores de inglês em formação com base em um checklist adaptado de Prensky (2012).

Como mencionado anteriormente, o ato de jogar é motivador e propicia a oportunidade de engajamento no processo de ensino-aprendizagem de maneira espontânea. Além disso, a ação de jogar on-line faz parte das atividades de crianças e adolescentes (COMITÊ GESTOR DA INTERNET NO BRASIL, 2012). Dessa forma, acreditamos que a inclusão de jogos educativos no ensino de língua inglesa possa colaborar para o desenvolvimento de uma aprendizagem significativa do idioma.

Neste trabalho, entendemos a aprendizagem significativa sob o ponto de vista de Rogers (1969), que a define a partir de cinco elementos:

1. envolvimento pessoal $-a$ aprendizagem significativa pressupõe um

\footnotetext{
${ }^{7}$ Aqui entendidos como jogos construídos e com usabilidade em suportes tecnológicos eletrônicos ou computacionais.
} 
envolvimento pessoal de qualidade, uma vez que considera que o evento da aprendizagem afeta a pessoa por completo, tanto no que diz respeito a sentimentos quanto a aspectos cognitivos;

2. autoiniciação - mesmo que a aprendizagem aconteça a partir de um estímulo externo, o sentimento de descoberta, de atingir um objetivo ou de compreender algo, vem do interior da pessoa;

3. integração - a aprendizagem significativa é "penetrante", ou seja, é incorporada ao indivíduo e suscita modificação de comportamento, atitudes e talvez até da personalidade do aprendiz;

4. avaliação - a aprendizagem significativa prevê que o aprendiz avalie se uma atividade satisfaz suas necessidades e contribui para ampliar seu conhecimento na área;

5. significado - a aprendizagem significativa faz sentido para o aprendiz durante toda a experiência.

O último elemento é essencial para que a aprendizagem significativa ocorra. Rogers (1969) afirma que o processo de aprendizagem é intrínseco ao ser humano, mas a realidade de cada indivíduo atua como "mola propulsora" para a aprendizagem. Portanto, cada educando reage de uma forma diferente ao conteúdo apresentado dependendo de quão próximo está de sua realidade e do seu interesse pessoal. Dessa forma, pode-se dizer que a aprendizagem significativa, segundo Rogers (1969), visa ao envolvimento pessoal do indivíduo a partir de sua maneira de ser e atuar no mundo, o que possibilita que seja autoiniciante e propicie um senso de descoberta.

Além disso, o autor ressalta que a aprendizagem significativa prevê a autossatisfação. Dessa forma, é necessário que o aprendiz se sinta acolhido no contexto de ensino-aprendizagem. Portanto, para Rogers (1969), o apoio e a compreensão empática são essenciais para uma aprendizagem bem-sucedida.

Em resumo, poderíamos definir a aprendizagem significativa, sob a perspectiva de Rogers (1969), como aquela que, partindo da realidade do aprendiz, satisfaz suas necessidades e, envolvendo-o, de modo consciente afetiva e cognitivamente, amplia seus conhecimentos e possivelmente modifica comportamentos e atitudes.

Depois de termos discorrido sobre os conceitos teóricos que embasam este artigo, apresentaremos a seguir o contexto para o qual as atividades em foco foram desenhadas bem como sua descrição.

\section{Metodologia}

Este artigo relata um estudo de caso do qual participaram duas alunas, com 10 e 15 anos, respectivamente, além da professora de inglês e de uma das pesquisadoras coautoras deste texto. 
As atividades apresentadas neste artigo fazem parte de uma unidade didática que visa a ensinar como descrever pessoas famosas em inglês mencionando suas características físicas, de personalidade, principais trabalhos e rotina diária. Criadas com o intuito de serem ministradas a adolescentes que estão começando a aprender inglês, as atividades foram delineadas na plataforma Kahoot em sistema de questionários on-line, com características de um jogo educativo.

Essas atividades foram pilotadas pela professora participante em aulas particulares para as duas alunas que cursavam inglês há um semestre no momento em que as atividades foram ministradas e eram iniciantes na aprendizagem do idioma. A aplicação aconteceu durante 3 aulas de 60 minutos de duração cada, em três semanas consecutivas, e foi observada por uma das coautoras deste artigo. A pesquisadora realizou notas de campo e fez algumas perguntas pontuais sobre a utilização do jogo para o desenvolvimento das atividades no sentido de levantar a opinião das estudantes acerca de sua utilização.

\subsection{O Kahoot}

O Kahoot é uma plataforma digital on-line interativa que utiliza elementos dos jogos a partir dos quais há possibilidade de criar um jogo educativo com perguntas de múltipla escolha às quais podem ser adicionados vídeos, imagens, diagramas etc. que podem servir como base para a realização da atividade. Para jogar, o participante não precisa de uma conta e nem baixar o jogo e sua participação acontece por meio do acesso à tela de respostas diretamente no site https://kahoot.it/\#/, digitando-se um número PIN que é disponibilizado pelo professor.

Os jogos criados na plataforma Kahoot podem ser jogados em duplas ou em grupos e possibilitam a criação de três tipos de atividades: quiz, discussion e survey. A tipologia quiz consiste em perguntas de múltipla escolha que podem variar desde questões de interpretação de texto (oral ou escrito) até revisão de vocabulário, gramática, conceitos etc. Nessa tipologia, o feedback é imediato, pois a resposta certa é apresentada logo depois que todos os jogadores clicarem em suas respectivas opções. Já por meio da discussion é possível elaborar uma pergunta também de múltipla escolha, para a qual não existe uma única resposta correta. Essa tipologia é utilizada para fomentar o debate em sala de aula. Por fim, a tipologia survey funciona como uma enquete, levantando opiniões dos participantes acerca de um determinado assunto.

As três tipologias apresentam a possibilidade de determinar o tempo para a resposta, o que facilita o gerenciamento do jogo em grupo. Enquanto pensam na resposta, os jogadores ouvem uma música característica do jogo como pano de fundo. A tipologia quiz permite ainda que as respostas dos alunos sejam pontuadas, o que promove um ambiente de competição e os nomes dos alunos com pontuação mais alta aparecem no topo da lista na tela das questões. O objetivo dos jogos educativos criados no Kahoot é responder às perguntas de múltipla escolha e, para tanto, os jogadores utilizam seus 
próprios dispositivos (celulares, tablets, notebooks etc.) para escolher a resposta mais adequada para uma pergunta que é exposta a todos, geralmente por meio de projeção multimídia.

Para ter acesso ao jogo, os alunos precisam digitar o número PIN que aparece apenas na tela de quem o criou, na tela das perguntas, neste caso, do professor, que deve fornecê-lo aos participantes. Uma vez conectado, cada aluno deve escrever um pseudônimo e clicar em “Ok, go!” para entrar no jogo, mas é o professor quem dá início, clicando no botão "start", em sua própria tela. Em seguida, as questões do jogo são apresentadas uma a uma, e geralmente são projetadas em uma tela para que todos os jogadores (alunos) possam vê-las com as respectivas alternativas de respostas. Os jogadores respondem as questões em seus dispositivos móveis selecionando um dos quatro botões correspondentes a cada uma das respostas possíveis. A pontuação é calculada pelo tempo de resposta e pela precisão.

Essas são, em linhas gerais, as características da plataforma Kahoot. Na próxima seção, descreveremos, a seguir, as atividades estudadas neste artigo.

\subsection{Atividades para descrição de pessoas famosas usando o Kahoot}

Como mencionado anteriormente, as atividades em foco neste trabalho foram desenvolvidas como parte de uma unidade didática que tem por objetivo descrever pessoas famosas. Para tanto, as alunas precisaram utilizar as seguintes funções comunicativas: dizer a profissão da pessoa, descrevê-la fisicamente, descrever traços de sua personalidade; falar sobre seus principais trabalhos e sobre sua rotina.

As atividades em foco neste estudo visaram a revisar o conteúdo apresentado e praticado em aulas anteriores de forma lúdica e motivadora para as alunas. Para sua elaboração, contou-se com a colaboração das alunas que indicaram nomes de cantores famosos de suas preferências para servir de base para a preparação do jogo.

A primeira atividade, intitulada "describing people 1", utilizou um chart com ilustrações e vocabulário relacionado à descrição física de pessoas como imagem introdutória, um vídeo clip da música "Chandelier", interpretada pela cantora Sia, além de quatro fotos da artista. Essa cantora foi escolhida pela aluna de 10 anos .

Ao entrar no jogo, as alunas assistiram ao vídeo clip da cantora com o intuito de familiarizarem-se ou lembrar das características físicas da cantora. Nesse vídeo, Sia está com um collant, meia-calça e sapatilhas de ballet e dança durante toda a música. O vídeo foi escolhido por possibilitar que as alunas a vissem para que pudessem observar suas características físicas. A música em si não foi trabalhada nesta atividade, funcionando apenas como pano de fundo. Depois de assistir ao vídeo, as alunas começaram a jogar. $\mathrm{O}$ objetivo deste jogo, composto por seis perguntas, foi revisar o vocabulário utilizado para descrever pessoas fisicamente. Para tanto, a cada pergunta foi adicionada uma foto 
diferente e o nome da cantora não foi mencionado, pois esperava-se que as alunas a reconhecessem logo que vissem. As perguntas apresentadas foram:

1 - She has...

a) long curly blond hair

b) long wavy blond hair

c) straight long blond hair

d) wavy long blond hair

2 - She has...
a) blue almond eyes
b) almond blue eyes
c) round blue eyes
d) blue wide ser eyes

4 - She is...
a) fair skinned
b) bronzed
c) olive skinned
d) black

5. She is ${ }^{8}$
a) tall
b) medium height
c) short
d) quite short

A segunda atividade, intitulada "character traits", por sua vez, objetivou revisar vocabulário relativo a traços de personalidade anteriormente apresentados, que também são utilizados ao descrevermos pessoas. Como a anterior, constituiu-se em um quiz com perguntas de múltipla escolha e foi elaborada a partir de uma música interpretada por Shawn Mendes, cantor indicado pela garota de 15 anos. Da mesma forma que primeira atividade, esta iniciou com a apresentação do vídeo clip, no entanto, aqui a letra da música serviu como insumo para a realização da tarefa. A música utilizada foi "Treat you better", que apresenta uma adolescente vítima de maus tratos tanto física como psicologicamente pelo namorado e um garoto apaixonado por ela que tenta convencê-la a ficar com ele.

Como a proposta era trabalhar com alunos iniciantes, ao apresentar o vídeo clip, foram disponibilizadas as legendas em inglês para que a atividade se tornasse uma atividade de leitura. Dessa forma, o entendimento da ideia central da música deu-se a partir da compreensão escrita e não oral.

\footnotetext{
${ }^{8}$ a esta questão foi anexado um vídeo que mostra pessoas com várias estaturas e a conversão de medidas de pés/polegadas para o sistema métrico. As alunas assistiram ao vídeo para estabelecer uma relação com a estatura da cantora.
} 
Após assistirem ao clip lendo a letra da música nas legendas, as alunas começaram a jogar. $\mathrm{O}$ objetivo foi que respondessem corretamente cinco questões relativas às personalidades das personagens que aparecem na música e três questões relacionadas ao assunto tratado na música. As perguntas propostas foram:

1) Shawn is...
a) considerate
b) mean
c) cowardly
d) disrespectful

2) The girl's boyfriend is..
a) sincere
b) respectful
c) reliable
d) fierce

3) The girl's boyfriend is...
a) easygoing
b) hardworking
c) stressful
d) trustful

4) Shawn is...
a) thoughtfulness
b) stingy
c) grouchy
d) awesome

5) The girl's boyfriend is...
a) trustworthy
b) caring
c) cold-hearted
d) witty

6) The song "Treat you better" is about a girl who...
a) has an awesome boyfriend
b) is happy in her love relationship
c) doesn't like her boyfriend
d) isn't treated well by her boyfriend

7) Shawn promises the girl that...
a) he will love her for the rest of her life
b) he will beat her boyfriend up
c) he will be thoughtful
d) he will make her fall in love with him

8) Which is the best alternative to summarize what Shawn wants to tell the girl? 

a) I'm just as good for you
b) You're better than that
c) You deserve better
d) He deserves the best

Como mencionado, essas atividades serviram de base para uma proposta de inserção do uso de um recurso tecnológico digital no ensino de inglês ao mesmo tempo que buscaram oferecer uma oportunidade para o desenvolvimento da aprendizagem significativa. Suas características enquanto jogo educacional digital e potencialidade para propiciar esse tipo de aprendizagem serão discutidas na próxima seção.

\section{Discussão}

Como podemos observar a partir das descrições na seção anterior, as atividades propostas na plataforma Kahoot apresentaram características da gamificação, como a presença de narrativa, feedback imediato, pontuação, competitividade, música e possibilidade de diversão, elementos que geralmente compõem os jogos. Por essa razão, consideramos que possam ser classificadas como jogo digital educativo on-line.

Na primeira atividade, a narrativa, um dos elementos presentes em jogos, aparece no vídeo clip da cantora, no entanto, o objetivo principal do jogo é que as alunas percebam as características físicas da artista. Isso denota que, apesar de esse elemento do jogo poder ser observado na atividade, ele não assume o papel essencial de narrativa em si, pois não é necessário que as alunas compreendam a narrativa para que possam jogar.

A segunda atividade, por sua vez, também apresenta uma narrativa por meio do vídeo clip, mas, neste caso, a letra da música é fornecida nas legendas para servir de insumo para que as alunas respondam as três últimas questões propostas na atividade. Assim, nota-se que, diferentemente do que ocorre na atividade 1, a narrativa apresentada faz parte do jogo, tornando-se um desafio e não apenas um elemento de estética, como ocorrera na atividade anterior.

Percebe-se ainda que, apesar de as duas atividades apresentarem narrativas, apenas a segunda o faz com o intuito de compor o jogo. No entanto, ambas apresentam elementos de mecânica, dinâmica e estética trabalhando juntos, característicos dos jogos, como desafio, feedbacks rápidos, pontuações, competição e placares.

No que diz respeito aos objetivos das atividades propostas, nota-se que ambas visaram a praticar vocabulário específico relacionado à situação de descrição de pessoas, seja fisicamente ou por meio de suas características de personalidade, que haviam sido previamente trabalhados. Entretanto, a proposta não foi simplesmente revisar o conteúdo apresentado de maneira isolada, mas colocá-lo em prática de uma maneira lúdica e utilizando elementos do dia a dia, o que possibilitou a utilização do idioma em situações reais. 
O fato de a prática de uso da língua ter sido realizada por meio de um jogo educativo digital on-line, cujas perguntas foram apresentadas na tela do computador e as respostas dadas por meio dos respectivos celulares das alunas, tornou as atividades motivadoras e prendeu a atenção das estudantes, por relacionarem-se a algo de interesse das mesmas, os artistas. Os dois artistas descritos em ambas as atividades foram escolhidos pelas alunas, o que fez com que houvesse um envolvimento ainda maior com o jogo educativo digital, não apenas porque jogos digitais fazem parte de seu cotidiano, mas porque estabeleceram uma relação afetiva com o conteúdo trabalhado nas atividades, uma vez que estavam descrevendo seus respectivos ídolos.

Nesse sentido, além da evidência de elementos que compõem os jogos, nota-se a presença de elementos que caracterizam a aprendizagem significativa (ROGERS, 1969), pois a descrição de seus próprios ídolos levou a um "envolvimento pessoal" das alunas", pois as atividades, mesmo iniciadas pela professora, fizeram sentido para as meninas por fazerem parte de seu cotidiano. É verdade que essas mesmas atividades poderiam ter sido realizadas sem a utilização do jogo digital e, pelo fato de mobilizarem os sentimentos das alunas em relação a seus ídolos e às suas próprias realidades, seriam consideradas atividades que promoveriam a aprendizagem significativa. Entretanto, por terem sido mediadas pelo jogo educativo digital, houve um envolvimento ainda maior com as atividades, pois além do conteúdo abordado, o recurso didático utilizado também estimulou a participação, visto que ambas gostam de atividades lúdicas, principalmente disponibilizadas por meio de dispositivos eletrônicos.

Pôde-se verificar ainda a presença de mais um elemento que compõe a aprendizagem significativa: a autoniciação. Isso ocorreu porque as alunas, por si mesmas, sentiram-se interessadas em fazer a atividade. Além disso, o fato de estarem lidando com uma plataforma por elas desconhecidas até então possibilitou também a "sensação de descoberta", outro fator importante para o desenvolvimento da aprendizagem significativa.

É importante ressaltar que, apesar de as atividades propostas terem oferecido uma possibilidade para as alunas terem uma experiência engajadora no contexto de aprendizagem da língua inglesa, alguns aspectos relacionados à leitura crítica deixaram de ser trabalhados. O fato de a letra da música "Treat you right", interpretada por Sean Mendes, apresentar o tema de violência contra a mulher não foi explorado. Assim, tanto a professora quanto a pesquisadora julgaram necessária a criação de uma terceira atividade por considerarem ser responsabilidade dos professores a formação crítico reflexiva dos adolescentes. Dessa forma, mais uma atividade via Kahoot foi proposta: a interpretação do vídeo "Violence against women throughout the life", uma animação em inglês que mostra situações de violência física e psicológica de maneira lúdica e leve sobre a violência contra a mulher.

Ainda no que diz respeito às características da aprendizagem significativa, pôdese observar que as atividades estimularam as alunas a tomarem consciência acerca de seus processos de aprendizagem, uma vez que todas as vezes que perceberam ter errado uma 
questão, pediram para jogar novamente. A refacção da atividade teve como objetivo analisar as alternativas com mais cuidado e buscar entender o que tinham errado. Foi possível perceber, assim, que as estudantes assumiram uma postura ativa em seus respectivos processos de ensino-aprendizagem, monitorando seus erros e discutindo-os tanto com a colega quanto com a professora.

\section{Considerações finais}

Os objetivos deste artigo foram apresentar duas atividades elaboradas na plataforma digital Kahoot que fazem parte de uma unidade didática para o ensino de inglês como língua estrangeira e analisar seu potencial para o desenvolvimento de aprendizagem significativa.

O primeiro questionamento que fizemos em relação à utilização desse recurso foi se o jogo digital contribuiria para uma aprendizagem significativa e como essa aprendizagem seria diferente daquela que acontece sem o uso de recursos digitais. Isso porque as atividades propostas por meio do jogo digital não passaram de perguntas de múltipla escolha que poderiam ter sido feitas via material impresso.

Em relação a esse aspecto, foi possível perceber que a utilização das atividades criadas a partir de escolhas realizadas pelas próprias alunas em si configurou-se em uma possibilidade de desenvolvimento da aprendizagem significativa, pois as estudantes sentiram-se envolvidas com o conteúdo visto que estavam discutindo as características de seus ídolos. Além disso, o fato de utilizarem o jogo educacional digital para tanto fez com que sua motivação aumentasse, pois a sensação de descoberta, a curiosidade, a fantasia, o desafio não se deram apenas em relação ao conteúdo abordado, mas também relacionaram-se ao processo de jogar para realizar a atividade de maneira reflexiva e estratégica. A existência da competição, por haver uma pontuação individual visível no placar, e da música, elementos presentes nos jogos, também engajaram as estudantes a participar do jogo em si, motivadas simplesmente pelo ato de jogar. Dessa forma, pôdese observar mais um elemento característico da aprendizagem significativa, a autoiniciação.

Também pudemos notar que as atividades contribuíram para a participação ativa das alunas em seus respectivos processos de ensino-aprendizagem uma vez que o feedback imediato disponibilizado de maneira lúdica por meio das respostas automáticas do jogo, com suas devidas pontuações, estimulou-as a refazer as atividades na busca de acertar cada vez mais, o que provavelmente não teria ocorrido se as perguntas de múltipla escolha tivessem sido apresentadas como quiz em material impresso. Dessa forma, é possível concluir que as atividades aqui apresentadas não só criaram uma oportunidade para o desenvolvimento da aprendizagem significativa, por meio da utilização da língua em um contexto real, como também estimularam a construção de novos conhecimentos mediados pela gamificação presente no Kahoot, por meio de sua mecânica, dinâmica e 
estética. Conhecimentos esses que extrapolaram os objetivos da unidade didática em si (descrever pessoas famosas), incluindo também a compreensão das regras do jogo, disponibilizadas em inglês na plataforma e, portanto, constituíram-se em mais uma oportunidade para que as alunas fizessem uso da língua em uma outra situação comunicativa e interativa.

Apesar de as atividades propostas terem fornecido uma oportunidade para o desenvolvimento da aprendizagem significativa, notamos que as questões ficaram restritas ao conhecimento factual. Assim, uma terceira atividade visando à reflexão sobre o assunto abordado na música apresentada na atividade 2 foi proposta. A nosso ver, seria interessante investigar como a plataforma digital Kahoot poderia ser utilizada para fomentar a reflexão. Dessa forma, pensamos ser importante propor futuras pesquisas com foco não apenas na utilização do jogo digital on-line em si como recurso para o ensinoaprendizagem de língua inglesa, mas como ferramenta para o desenvolvimento de uma aprendizagem crítico-reflexiva.

\section{Referências bibliográficas}

ALVES, F. Gamefication: como criar experiências de aprendizagem engajadoras. DVS Editora, 2014. Disponível em: < http://www.saraiva.com.br/gamification-como-criarexperiencias-de-aprendizagem-engajadoras-um-guia-completo-8114828.html $>$. Acesso: 10 jan. 2017.

ARAÚJO, M. Ensino-aprendizagem de jogos digitais na formação inicial do professor de inglês. VI CLAPFL - Congresso Latino-americano de Formação de Professores de Linguas. UEL, Londrina, 25 a 27 out. 2016, mimeo.

ASEAN COMMISSION ON THE PROMOTION AND PROTECTION OF THE RIGHTS OF WOMEN AND CHILDREN; MINISTRY OF SOCIAL DEVELOPMENT AND HUMAN SECURITY; UNITED NATIONS WOMEN. Violence against women throughout the life, 2015. Disponível em: $<$ https://www.youtube.com/watch?v=vIsdFwCCyRU $>$ Acesso em: 01 dez. 2016.

BARCELOS, F.A.A. Aprendendo inglês em jogos on-line: um relato sobre nativos digitais. 19f. Trabalho de conclusão de curso (TCC) - Letras, Universidade Federal do Triângulo Mineiro, Uberaba, 2010.

BERGMANN, J.; SAMS, A. Flip Your Classroom: reach every student in every class every day. Eugene, Oregon: ISTE, 2012.

BERRETT, D. How 'flipping' the classroom can improve the traditional lecture. The Chronicle of Higher Education, Feb. 19, 2012.

BLANCO, G. 2015. Gamification: como a lógica dos jogos pode te ajudar a resolver problemas. DRAFT. Disponível em: $<$ https://www.napratica.org.br/gamification-comoa-logica-dos-jogos-pode-te-ajudar-a-resolver-problemas>.Acesso em: 06 dez. 2016.

BOTTENTUIT JR., J.B. Do computador aos tablets: vantagens pedagógicas na utilização de dispositivos móveis na educação. Revista EducaOnline - Educomunicação, Educação e Novas Tecnologias, Universidade Federal do Rio de Janeiro - Escola de 
Comunicação Laboratório de Pesquisa em Tecnologias da Informação e da Comunicação - LATEC/UFRJ , v.6, no.1,p.125-148, jan./abr., 2012. Disponível em: < file://D:/Documents/artigos/do_computador_ao_tablet.pdf> Acesso em: 15 nov. 2016. BRASIL. 2009. Ministério da Educação (MEC). Proinfo integrado. Disponível em: $<$ http://portal.mec.gov.br/index.php?option+com_contente\&view $=$ article\&id=13156 >. Acesso em: 15 nov. 2016.

BRASIL. Ministério da Educação. Portaria no. 1.322. Brasília, 6 de novembro de 2012. BRASIL. Ministério da Comunicação. Projeto Banda Larga nas Escolas. Brasília. Decreto $\mathrm{n}^{\mathrm{o}}$ 6.424, de 04 de abril de 2008.

BRASIL. Presidência da República - Casa Civil. Decreto $\mathbf{n}^{\mathbf{0}}$ 5.542, de 20 de setembro de 2005. Institui o Projeto Cidadão Conectado - Computador para Todos, no âmbito do Programa de Inclusão Digital, e doutras á providências. Disponível em < http://legislacao.planalto.gov.br/legisla/legislacao.nsf/Viw_Identificacao/DEC 5.5422005?OpenDocument> . Acesso em: 15 nov. 2016.

BRASIL. 1997. Ministério da Educação e do Desporto. Portaria no. 522, de 9 de abril de $1997 . \quad$ Brasília. Disponível em: < https://www.fnde.gov.br/fndelegis/action/UrlPublicasAction.php?acao=abrirAtoPublico $\&$ sgl tipo $=$ POR\&num ato $=00000522 \&$ seq ato $=000 \& v 1 r \_$ano $=1997 \&$ sgl orgao $=$ MED $>$. Acesso em: 15 nov. 2016.

CASTLE, S. How to use Kahoot! to teach new topics - blind kahoot!ing. Disponível em: $<$ https://getkahoot.com/blog/the-art-of-blind-kahoot-ing>.Acesso em: 01 dez. 2016. COSTIKYAN, G. I have no words \& I must design. Interactive Fantasy, 2. Disponível em:<http://www.costik.com/nowords.html>. Acesso em: 05 jul. 2017.

DETERDING, S.; SICART, M.; NACKE, L.; O’HARA, K.; DIXON, D. Gamification: using game-design elements in non-gaming contexts. Proceedings of the CHI '11 Extended Abstracts on Human Factors in Computing Systems, 2011, pages 2425-2428. Disponível em <http://portal.mec.gov.br/par/193-secretarias-112877938/seed-educacaoa-distancia-96734370/15808-programa-banda-larga-nas-escolas >. Acesso em: 15 nov. 2016.

FLANAGAN, M. Critical play: radical game design. Cambridge: MIT Press, 2009.

FUNDAÇÃO TELEFÓNICA VIVO. Juventude conectada 2. São Paulo: Fundação Telefónica Vivo, 2016.

GEDIGAMES. Relatório final: mapeamento da indústria brasileira e global de jogos digitais. Núcleo de Política e Gestão Tecnológica: PGT - Conhecimento, Inovação, Desenvolvimento, USP, fev. 2014. Disponível em: < http://www.bndes.gov.br/SiteBNDES/bndes/bndes_pt/Galerias/Arquivos/conhecimento/ seminario/seminario_mapeamento_industria_games042014_Relatorio_Final.pdf $>$

Acesso em: $01 \mathrm{dez} .2016$.

GEE, James Paul. 2009. Bons Videogames e Boa Aprendizagem. Perspectiva, Florianópolis, v. 27, n. 1, 167-178, jan./jun. 2009. Disponível em: $<$ http://www.perspectiva.ufsc.br/perspectiva_2009_01/James.pdf $>$ Acesso em: 06/2014. HEINCH, R., MOLENDA, M., RUSSELL, J., AND SMALDINO, S. Instructional Media and Technologies for learning. 7 ed. Englewood Cliffs, NJ: Prentice Hall, Inc., 2002.

HUIZINGA, J. Homo ludens: o jogo como elemento da cultura. 7.ed. São Paulo: Perspectiva, 2012. 
INSTITUTO BRASILEIRO DE GEOGRAFIA E ESTATÍSTICA (IBGE). Pesquisa nacional por amostra de domicílios, 2009. Disponível em: < http://www.ibge.gov.br/home/estatistica/populacao/trabalhoerendimento/pnad2009>.

Acesso em: 16 nov. 2016.

KAPP, K. The gamification of learning and instruction: game-based methods and strategies for training and education. Pfeiffer, 2012.

MALONE, Th. W. What makes things fun to learn? A study of intrinsically motivating computer games. 1980. Tese de doutorado, Stanford University, 1980.

OLIVEIRA, J. A. de; OLIVEIRA, C.C. Gêneros de jogos digitais e aprendizagem de inglês: vislumbrando uma relação. Anais do $3^{\circ}$ Encontro de Pesquisa e Extensão. Patrocínio, 2016. Disponível em: $<$ http://www.ifetec.com.br/evento/index.php/enpe/3enpe/paper/viewFile/118/42> Acesso em: 26 jan. 2016.

PETRY, A. dos Santos. Jogo, autoria e conhecimento: fundamentos para uma compreensão dos games. São Paulo: Editora Paco Editorial, 2014.

O jogo como condição da autoria e da produção de conhecimento: análise e produção em linguagem hipermídia. 2010. Tese de Doutorado em Comunicação e Semiótica - Pontifícia Universidade Católica de São Paulo, 2010.

PRENSKY, M. Não me atrapalhe, mãe: eu estou aprendendo! São Paulo: Phorte, 2010. ROGERS, C. Freedom to learn: a view of what education might become. Columbus, OH, Charles E. Merrill, 1969.

SANTAELLA, L. O papel do lúdico na aprendizagem. Revista Teias, vol.13, n. 30, p. 185-195, 2012.

Disponível em: http://www.periodicos.proped.pro.br/index.php/revistateias/article/viewFile/1371/978 Acesso em: 16 jan. 2017.

SANTAELlA, L.; FEITOZA, M. (orgs.). Mapa do jogo: a diversidade cultural dos games. São Paulo. Editora Cengane Learning, 2009.

SANTOS, S. M. P. Educação, arte e jogo. Petrópolis. Editora Vozes, 2006.

SILVEIRA, L. S. de. Ensino e aprendizagem de língua inglesa e recursos tecnológicos: um estudo sobre os processos de retroação e irreversibilidade. Domínios de Linguagem. vol. 6. $\quad$ n. 2, p.19-40, 2012. Disponível em: < http://www.seer.ufu.br/index.php/dominiosdelinguagem/article/view/18271> . Acesso em: 26 jan. 2017.

TED Ideas worth spreading. How TED works. Disponível em: $<$ https://www.ted.com/about/our-organization/how-ted-works $>$. Acesso em: 10 jan. 2017.

UNITED NATIONS WOMEN. Ending violence against women and girls: if not you, who? 2016. Disponível em: <https:/www.youtube.com/watch?v=W_ZPHPutN-c $>$ Acesso em: 01 dez. 2016.

WERBACH, K.; HUNTER, D. For the win: how game thinking can revolutionize your business. Filadélfia, Pensilvânia: Wharton Digital Press, 2012.

WOLYNEC, E. Aprendizagem móvel em escolas e universidades. 2010. Disponível em: <http:/www.techne.com.br/artigos/O\%20uso\%20da\%20Inte rnet\%20Movel.pdf $>$. Acesso em: 15 nov. 2016.

ZIMMERMAN, E. Narrative, interactivity, play, and games: four naughty concepts in need of discipline. In: WARDRIP-FRUIN, N; HARRIGAN, P. (Eds.). First person. Cambridge: MIT Press, 2004. 
Maria Aparecida Gazotti-Vallim is an English teacher at The Brazilian Federal Institute of Education, Science and Technology (IFSP-previously called CEFET) and holds an M.A. degree in Applied Linguistics from the Catholic University of São Paulo (PUCSP) where she is currently a PhD. student. She has worked as an English teacher at private universities such as: COGEAE-PUCSP, Fundação Álvares Penteado (FECAP), São Paulo State College of Technology (FATEC), Centro Universitário Ibero Americano (Unibero) and as a researcher of the Group of Research in Teaching and Learning Languages for Specific Purposes (GEALIN). She has also worked with Teacher Education since 1991, first in the coordination of SENAC-Centro de Idiomas (language center) and, later, in in-service extramural courses offered by COGEAE, PUCSP, Universidade de Taubaté, as well as Language Institutes and the São Paulo Board of Education. In 2013, she coordinated an e-learning undergraduate teacher education program for teachers of technological areas at IFSP and in 2014 became the pedagogical director of the e-learning sector of this institution. Her main interests are: English for Specific Purposes; English Language Teaching; Teacher Education; Distance Learning; Textual genres; New Information and Communication Technologies; revising and translating technical and academic texts.E-mail: cgazotti@gmail.com

Silvia Trentin Gomes holds an M.S. in Technologies of Intelligence and Digital Design from PUCSP where she is currently a PhD. student and researches cognitive processes and digital environments with core interest in esthetic education, teaching of arts and games. She is a specialist in Visual Arts: Culture and Creation from SENAC Porto Alegre. Graduated in Artistic Education with a degree to teach Plastic Arts from Universidade de Passo Fundo, Rio Grande do Sul, Brazil, she has also taught at the programs of Visual Arts, Graphic Design, Fashion Design and Pedagogy from that university. She has also taught arts and education at Colégio Municipal Carlos Gomes and Colégio Sinodal Sete de Setembro (elementary schools). Gomes is in charge of social and cultural projects in Arts and a director and teacher at the Contraste Artes Ateliê, where she has provided drawing and painting courses for children, youngsters and adults since 1998. E-mail: silviatrentin88@yahoo.com.br

Cynthia Regina Fischer is a PhD and an M.A. in Applied Linguistics from the Catholic University of São Paulo (PUCSP). She is currently the director of one of IFSP's campi in the city of São Paulo (campus Pirituba), an International Relations Adviser and also an English teacher at the same institution where she was the Pro-rector of Education from 2013 to 2014. From 2004 to 2014, she was a researcher of the Group of Research in Teaching and Learning Languages for Specific Purposes (GEALIN). From 2012 to 2014, she coordinated an e-learning undergraduate teacher education program for teachers of technological areas at IFSP. From 2001 to 2010, she coordinated the undergraduate program for Trilingual Executive Secretariat at Fundação Álvares Penteado (FECAP). Her main interests are: English for Specific Purposes; English Language Teaching; 
The ESPecialist: Descrição, Ensino e Aprendizagem, Vol. 38 No. 1 jan-jul 2017 https://revistas.pucsp.br/esp CThe ESPecialist ISSN 2318-7115

Teaching Reading; Teacher Education; Distance Learning; New Information and Communication Technologies.E-mail:fischercr@uol.com.br 